\title{
História da EdUCAÇÃo MUSICAL E A EXPERIÊNCIA DO CANTO ORFEÔNICO NO BRASIL
}

\author{
History OF THE MUSIC EDUCATION AND THE EXPERIENCE \\ OF THE CHORUS SINGING IN BRAZIL
}

\author{
Wilson Lemos Júnior \\ Doutorando em Educação - Pontifícia Universidade Católica do Paraná; \\ Mestre em Educação - Universidade Federal do Paraná; \\ Docente do Instituto Federal Catarinense - Campus Araquari. \\ juniorlem@gmail.com
}

\begin{abstract}
Resumo: $\mathrm{O}$ ensino de música sempre esteve presente na história da educação brasileira porém, durante a primeira metade do século $\mathrm{XX}$, apresentou uma grande expansão principalmente após a defesa dos educadores do movimento da escola nova - caso dos pedagogos Fernando de Azevedo e Anísio Teixeira inclusive do músico e maestro Heitor Villa-Lobos. Neste artigo analisa-se o processo de valorização e implantação do ensino de música e do canto orfeônico nas escolas brasileiras. Busca-se analisar no discurso desses personagens, as suas ideias a respeito do ensino de música, assim como as suas finalidades, suas vantagens e sua relação com a escola moderna.
\end{abstract}

Palavras-chave: Canto orfeônico. Educação musical. História das disciplinas.

Aвstract: The teaching of music was always present during the periods of the history of the Brazilian education, but during the first half of the twentieth century, had a boom especially after the defense of the movement of educators of the new school, as the teachers Fernando de Azevedo and Anísio Teixeira and as the musician and conductor Heitor Villa-Lobos. In this article are discussed the process of recovery and the deployment of teaching music and chorus singing in the Brazilian schools. It tries to analyze the discourse of these characters, their ideas concerning music education, as well as their purposes, their advantages and their relations with the modern school.

KeY words: Chorus singing. History of the disciplines. Music education. 


\section{Consideraçóes a respeito da história da educação musical no Brasil}

Os primeiros indícios sobre o ensino da música no Brasil coincidem ao período do descobrimento, especialmente após a chegada dos jesuítas de Portugal. Nesse período, nota-se que a música servia como ferramenta de transmissão da religião e da cultura europeia aos índios brasileiros. $\mathrm{Na}$ ocasião a educação musical estava voltada ao modo europeu de promover a educação e a prática musical em igrejas, conventos e colégios. Com a chegada da família real ao Brasil, no ano de I808, a música estendeu-se para os teatros ao invés de ficar restrita à Igreja, porém, quanto ao ensino de música, não há indícios de grandes alterações metodológicas em relação ao período anterior, uma vez que esses ensinamentos mantinham-se presos a métodos progressivos com grande ênfase na memorização. Apesar de presente desde o descobrimento foi somente em I854 que se instituiu oficialmente o ensino de música nas escolas públicas brasileiras, e apenas em I890 é que se passou a exigir, legalmente, a formação específica para o professor de música.

Mesmo com as exigências legais na segunda metade do século $\mathrm{XIX}$, o ensino de música não se fortaleceu no início do século XX, porém durante a década de I920, surgiram algumas importantes contribuições a favor da expansão do ensino de música no país, caso dos defensores da escola nova no Brasil: Anísio Teixeira e Fernando de Azevedo. $\mathrm{Na}$ década seguinte, soma-se a contribuição do maestro Heitor Villa-Lobos que defendeu uma reformulação do ensino de música junto ao governo brasileiro. Surge, assim, a disciplina de

Canto orfeônico que passa a ser contemplada nas leis e decretos federais para o Ensino Básico. Após as reformas de ensino de Francisco de Campos, em i93 I e de Gustavo Capanema, em i942, o governo federal procurou expandir e tornar o ensino do Canto Orfeônico obrigatório na escola, não apenas no ensino primário, como também no ginasial.

O início da ditadura militar ocorrido no ano de 1964 no Brasil trouxe a necessidade de adequar a educação brasileira ao novo período político do país, com isso o ensino do canto orfeônico muda de nome, passando para Educação Musical, em 1964 e, em I97I, o ensino de música é extinto dos currículos escolares, sendo substituído pela Educação 
Artística, que mantinha um caráter interdisciplinar, pois havia ênfase nas quatro linguagens artísticas, sendo elas: a dança, a música, o teatro e as artes plásticas. Neste artigo propóe-se uma investigação acerca da expansão do ensino de música e do canto orfeônico durante as décadas de 1920 a I940, período em que a disciplina se afirmou no cenário educacional brasileiro.

\section{O canto orfeônico no Brasil}

Pode-se dizer que a inclusão da disciplina de canto orfeônico nas escolas brasileiras se deve, principalmente, à colaboração de dois personagens principais. O primeiro é um grupo que ficou conhecido como os defensores da Escola Nova no Brasil e, o segundo, foi com o maestro Heitor Villa-Lobos que lutou pela consolidaçáo do ensino do canto orfeônico nas escolas brasileiras. Serão abordadas, neste artigo, um pouco da trajetória desses dois personagens, assim como suas atuações dentro do cenário educacional do país.

No final da década de 1920 e início da década de 1930, ganhava força no Brasil, um grupo de educadores que se intitulavam os defensores da escola nova, que pregavam uma educação para todos, ou seja, que pudesse abranger as camadas mais carentes da sociedade. A presença marcante de alguns destes intelectuais como Fernando de Azevedo, Lourenço Filho e Anísio Teixeira no mercado editorial, nas gestóes dos sistemas de instrução pública e até mesmo na formulação de políticas educacionais, fez com que as ideias destes educadores fossem propagadas por todo o país. Tais intelectuais se preocupavam com o ensino de música, tanto para as escolas primárias como para as secundárias:

Segue-se, na então Capital do país, a Reforma de Anísio Teixeira, em 1932, que já encontrou estruturada a de seu antecessor, Fernando de Azevedo, a qual, em virtude da Revoluçáo de 1930, não pôde ter o desenvolvimento almejado. Na Reforma de 1932, a Música e as demais Artes têm um lugar proeminente, como um dos mais preciosos alicerces da Escola Nova. Além da programação para Escolas Elementares, Jardins de Infância 
e Ginásios, é criada a Cadeira de Música e Canto Orfeônico no Instituto de Educação e que foi ministrada pela Professôra Ceição de Barros Barreto [...] (JANNIBELLI, I972, p. 42).

O projeto escolanovista defendia uma educação para as massas, especialmente para a crescente populaçáo que habitava os grandes centros urbanos e servia de mão de obra barata para o também crescente movimento industrial. A música tinha um importante espaço neste olhar sobre a educação. Essa relaçáo se dava exatamente no sentido de despertar a cidadania. A finalidade educativa da música, mais tarde iria ao encontro da política nacionalista de Getúlio Vargas que, desde o início de seu governo, buscou uma centralização do poder, lutando contra a política regionalista praticada durante a Primeira República. A administraçáo do país tinha que ser única e independente dos proprietários rurais que apoiavam e eram apoiados pelo Governo Federal no período da política do café com leiter.

Sendo assim, a afirmação de uma nação era uma das bandeiras do governo getulista e a música era uma poderosa ferramenta a favor de uma unificação artística, musical e política.

Na obra Novos caminhos e novos fins: a nova política da educação no Brasil. Subsidios para uma história de quatro anos, com primeira edição no ano de 1937, Fernando de Azevedo analisou a reforma educacional planejada e executada por ele, no Rio de Janeiro, entre os anos de 1927 a 1930. Em sua análise o autor defendia o ensino das artes apoiado no poder recreativo desta área de conhecimento: "A educação nova quebraria o ritmo da unidade essencial da vida, se, no seu propósito social, não abrangesse, para desenvolver o bem-estar do indivíduo e da comunidade, as poderosas inspiraçôes da arte, nos seus aspectos educativos e recreativos". (AZEVEDO, 1958, p.I19).

Se por um lado, Fernando de Azevedo considerou importante um espaço para as artes na nova proposta educacional, compreendendo as suas mais diversas manifestaçôes (desenhos manuais, música, teatro e dança), por outro, apresentou uma visão utilitarista da arte na escola, em que esta náo assumia papel essencial pelo seu lado técnico e teórico, mas sim pela sua capacidade recreativa. $\mathrm{O}$ ensino das artes era apresentado como um poderoso meio de educação, capaz de promover um dos valores 
essenciais para o homem da década de I920: a sociabililização. Esta, de fato, era uma preocupação dos intelectuais da escola nova que procuravam promover uma educação que preparasse o indivíduo para o convívio harmônico na sociedade. Dessa forma, descartavam os ideais de uma educação tradicionalista que apenas visava a instruçáo, ou seja, a simples transmissão de conhecimento. A respeito das diferentes artes, Fernando de Azevedo complementa:

No novo código de educação, as representaçôes dramáticas, a música e a dança não entraram apenas como divertimento nos programas de festas e reunióes escolares, mas se integraram, como num corpo de doutrina, no novo sistema com que a escola, aproveitando a arte na sua função social, como um auxiliar maravilhoso na obra de educação, poderá contribuir para aprofundar e consolidar as bases espirituais de nossa formação, abrindo a sensibilidade da criança as atividades ideais, capazes de despertá-la e desenvolvê-la, sem prejuízo, antes como proveito das práticas cotidianas. (AZEVEDO, I958, p. I28-I29).

Desta forma, Fernando de Azevedo criticava a arte dentro da educação tradicional.

A arte, que até então se hospedava, retraída, nos programas artificiosos de festas escolares, para deleite dos pais, no seu encantamento pelos filhos, incorporou-se ao sistema de educação popular, como um dos principais fatores educativos e uma das mais poderosas forças de ação, de equilíbrio e de renovação da coletividade [...] (AZEVEDO, I958, p.II8).

Para Azevedo, as atividades artísticas e musicais dentro da escola nova deveriam ser abordadas utilizando uma educação popular inspirada em motivos da vida infantil, da flora, da fauna e do folclore nacionais, o que também tornava necessários o recolhimento e a pesquisa dos cantos e cançóes populares provenientes do folclore. A utilizaçáo da arte folclórica na escola teria sua força maior na relação educativa com o aluno, e menor para apresentaçóes em reunióes e festividades escolares. 
O autor apresenta um ponto importante para a análise da música na escola, uma vez que ressaltava que durante a educação tradicional, os rituais e festividades escolares serviam apenas como "vitrine" e eram realizados apenas para deleite dos pais. Mais tarde, Villa-Lobos também se preocuparia com esta questão, uma vez que relatou que o excesso de apresentaçóes poderia ser prejudicial para o trabalho do professor em sala de aula. O sentido de "renovaçáo da coletividade" aparece no texto de Fernando de Azevedo, demonstrando novamente a afirmação de uma educação em busca da sociabilidade entre os estudantes. A ênfase em atividades em conjunto tornava-se então um dos elementos centrais para uma educação que privilegiava o ensino para as massas.

Assim como os defensores do ensino de música do início do século $\mathrm{XX}$, os intelectuais da escola nova também se inspiravam nos modelos de escolarização de países europeus. Percebe-se, por exemplo, que algumas das ideias de Fernando de Azevedo assumem um paralelo com a obra de um pedagogo francês chamado Chasteau em Liçôes de pedagogia (livro para o uso dos alunos da escola normal), publicado originalmente em I899 na França. Segundo esse manual:

A música eleva o espírito, estimula a sensibilidade, sôbre a qual se pode edificar todo o plano educativo. Representando o lado puramente estético da educação popular, até sôbre êste aspecto merece ser muito apreciada. - Depois, sob o ponto de vista moral, a música apresenta, para a juventude, uma poderosa couraça contra os perigos doutros prazeres, e isto pelo sentimento puro e elevado que ela cultiva. Finalmente sob o ponto de vista disciplinar, o canto que acompanha as marchas, os exercícios, as saídas e as entradas dos alunos, impede a desordem e o tumulto, ao mesmo tempo que ministra um alimento salutar à actividade nativa dos alunos, distraindo-os, alegrando-os, facilitando-lhes poderosamente o seu trabalho. É por isso que até o ensino de gimnástica costuma ser acompanhado dum canto bem ritmada (CHASTEAU, I899, p. 370).

Publicada e traduzida no Brasil, para o uso nas escolas normais ainda em I899, a obra de Chasteau, de certa forma, expressava uma das 
necessidades fundamentais para a formação de uma república. Ciente disso, Fernando de Azevedo nunca negou a influência direta das obras dos europeus. Neste sentido, algumas comparaçóes entre Chasteau e Azevedo se tornam inevitáveis, como por exemplo, a valorização do lado estético e moral. É certo que existem algumas diferenças, já que em nenhum momento Azevedo apresenta diretamente a música como forma de conter a desordem ou contra os "perigos doutros prazeres", tais como o álcool, o jogo ou a libertinagem. No entanto, a música assume abertamente uma função de controle tanto no discurso de Chasteau quanto no discurso de Azevedo, pois poderia oferecer essa elevação espiritual por meio de um ensino recreativo, capaz de distrair e alegrar os alunos, contendo, dessa forma, sua energia. A semelhança entre os discursos dos europeus e dos brasileiros como Fernando de Azevedo foi muito comum nesse período de busca pela renovação educacional.

Outro personagem importante na defesa do ensino de música no Brasil foi Heitor Villa-Lobos. Apesar do sucesso como músico, instrumentista e compositor, o maestro manteve um forte interesse pela educação, sendo decisivo no projeto de implantaçáo e divulgação do canto orfeônico nas escolas brasileiras. Durante a década de 1920, antes da sua segunda viagem à Europa, o maestro Villa-Lobos já possuía a ideia de criar coros populares nacionais, como demonstra um cronista do jornal carioca Folha da Noite, de 3 de novembro de I925:

Espírito de fina observação, Villa-Lobos notou que o costume admirável de cantar em coros ainda não penetrou nos povos latinos, sendo um hábito antigo na raça teutônica. $\mathrm{Na}$ Alemanha, cada indivíduo tem a sua voz determinada, com seu repertório de cançôes nacionais e, na primeira reunião em que se encontra, sabe executar a sua parte num concerto vocal. Na França já se começa a educar o povo com as músicas a vozes, sendo um exemplo incipiente o hino dos estudantes em greves, num cortejo qualquer pelas ruas de Paris.

É necessário que, também aqui, se intente o mesmo, começando pelas escolas, único ponto de seguros efeitos nas vindouras geraçóes de moços. Em lugar de encher a cabeça das crianças com os famosos hinos que nas escolas se cantam, de letra e de música 
estúrdias, sem a menor compreensão por parte, muitas vezes, até dos professores, é preciso que se ensine os pequenos a cantar as nossas cançóes apanhadas entre o povo, conseguindo que eles aprendam, cada qual a sua voz determinada, de modo que, no primeiro momento em que se encontre um grupo reunido, se possa, muito naturalmente, passar umas horas de agradável música. Mas a criança não poderá reter uma composição de várias vozes... Pois que não seja de muitas vozes, mas de duas apenas. E os nossos cantos, já estão fixados? Temos já cançôes nossas? Cançôes, temo-las e muitas; falta-nos somente quem as ame e as queira cantar. Da sistematização delas se encarregou o próprio Villa-Lobos e, muito breve, ouvi-las-emos nos seus adoráveis concertos. Dos coros passou a falar da nossa nomenclatura musical, dizendo que vai tudo muito errado, jamais sendo tango ou tanguinho o que hoje com tais nomes se publica (FOLHA DA NOITE, citado por KIEFER, I986, p. I42-I43).

Desde a década de 1920, a discussão que colocava o ensino musical distante da mera execução de hinários já estava presente. $\mathrm{O}$ ensino de elementos do folclore, na busca de resgatar uma identidade nacional, mostrava-

Por "tradição inventada" entende-se um conjunto de práticas, normalmente reguladas por regras tácita ou abertamente aceitas; tais práticas, de natureza ritual ou simbólica, visam inculcar certos valores e normas de comportamento através de repetição, o que implica, automaticamente; uma continuidade em relação ao passado. Aliás, sempre que possível, trata-se estabelecer continuidade com um passado histórico apropriado (HOBSBAWN, 1997, p. 9, grifo do autor?).

A disseminação da formação de uma cultura nacional se deu através das artes, da educação, da imprensa e do Governo, atendendo ao critério 
da "repetição", exposto por Hobsbawn. Essa relação com o nacionalismo não era uma exclusividade da música, uma vez que artistas das mais diversas áreas se empenhavam em divulgar a arte nativa brasileira, a cultura indígena e folclórica: Tarsila do Amaral, Anita Malfati e Di Cavalcanti na pintura; Mário de Andrade, Oswald de Andrade e Manuel Bandeira na literatura, e outros, que também estiveram empenhados ao que chamavam de resgate da cultura brasileira.

Após a Semana de Arte Moderna, o maestro Villa-Lobos manteve certa receptividade do público e da crítica paulistana. Este impacto rendeu-lhe uma bolsa para estudar na França, onde "[...] os viajantes e turistas brasileiros, desejosos de tomar o tradicional 'banho de civilização' em Paris, descobriram o quanto era 'importante' e 'genial' a cultura da população que os envergonhava pela miséria, ignorância e matiz da pele e que tanto seduzia os franceses [...]" (SVECENKO, 2000, p. 278279, grifos do autor).

Quando voltou ao Brasil, no ano de 1930, o consagrado compositor deparou-se com uma realidade musical bem diferente daquela que havia vivenciado na Europa. Se, por um lado, notava um público numeroso para a música, por outro, percebia que este público se encontrava aprisionado em "[...] esquemas rígidos e manipulado ao sabor das conveniências dos empresários [...]” (NÓBREGA, I970, p.II). Isso levaria Villa-Lobos a apresentar à Secretaria de Educação do Estado de São Paulo, por escrito, um plano de educação musical semelhante ao apresentado e ignorado, anteriormente, a Júlio Prestes, à época presidente do estado de São Paulo e candidato à presidência da República.

Após a revolução de outubro de I930, ano em que Getúlio Vargas assumiu a presidência da República, Villa-Lobos manteve ativas suas tentativas de reconstrução da educação musical brasileira, utilizando em seu discurso um forte apelo nacionalista, associado à defesa do folclore e da música brasileira de raiz. Em I2 de janeiro de 1932, Villa-Lobos entregava ao presidente Getúlio Vargas um memorial sobre o ensino de música e artes do Brasil. Neste documento, Heitor Villa-Lobos problematizava a questão artística brasileira no âmbito educacional, comparando-a novamente com as experiências realizadas em outros países. Além disso, o maestro apresentava a música como a melhor e a mais eficaz propaganda do Brasil para o exterior. 
Para Villa-Lobos, a música e as demais artes apareciam como elementos que deveriam ser valorizados por um governo preocupado com a formação de seus cidadãos. Ao justificar suas intençôes no trecho inicial da carta, Villa-Lobos acentuava o discurso nacionalista:

No intuito de prestar serviços ativos a seu país, como um entusiasta patriota que tem a devida obrigação de por à disposição das autoridades administrativas todas as suas funçóes especializadas, préstimos, profissão, fé e atividade, comprovadas pelas suas demonstraçôes públicas de capacidade, quer em todo o Brasil, quer no estrangeiro, vem o signatário, por este intermédio, mostrar a Vossa Excelência o quadro horrível em que se encontra o meio artístico brasileiro, sob o ponto de vista da finalidade educativa que deveria ser e ter para os nossos patrícios, não obstante sermos um povo possuidor, incontestavelmente, dos melhores dons da suprema arte. (VILLA-LOBOS, 1932).

O problema levantado por Villa-Lobos e a forma apresentada para a sua solução (exaltação ao nacionalismo) pareciam ser as melhores justificativas para a realização do seu projeto. Elevar a arte a um símbolo de potencial da Naçáo se tornava o principal argumento utilizado pelo maestro para conseguir atingir seus objetivos. Villa-Lobos sintetizava e defendia aquilo que já era realidade na Europa: o vínculo do ensino de música com uma função utilitarista para a sociedade.

$\mathrm{Na}$ reforma de ensino de 1932, de autoria de Anísio Teixeira, na capital do país, a música e as demais artes tinham lugar destacado dentro dos currículos escolares. $\mathrm{Na}$ Universidade do Distrito Federal (UDF), no ano de 1935, havia o curso de Formação de Professores Secundários de Música e Canto Orfeônico, com várias cadeiras culturais e pedagógicas. Em 1933, foi criada a Superintendência de Educação Musical e Artística, transformada em Serviço de Educação Musical e Artística (SEMA), no ano de 1939. Este também foi o ano em que Villa-Lobos apresentou sua proposta de ensino musical para os demais estados brasileiros:

Aos interventores e diretores de instrução de todos os estados do Brasil foi enviado em 1933 um apelo no sentido de que se 
interessassem pela propagação do ensino da musica nas escolas e pela organização de orfeóes escolares, apresentando-se ao mesmo tempo uma exposição das necessidades e vantagens que poderiam advir para a unidade nacional, da prática coletiva do canto orfeônico, calcada numa orientação didática uniforme. Foi êsse apelo acolhido com interesse e simpatia em muitos Estados que desde então se preocuparam em torna-lo uma realidade. Assim, resolveu-se aceitar a matrícula de professores estaduais nos cursos especializados, para pequenos estágios onde êles pudessem adquirir os conhecimentos básicos imprescindíveis. (VILLA-LOBOS, I946, p. 528).

Este projeto somente foi possível com a Superintendência que reunia cerca de 200 professores que ministravam o ensino da Música e Canto Orfeônico nas escolas de diversos níveis.

Entre as realizaçóes de Villa-Lobos dentro do SEMA destaca-se a atuação em defesa do canto orfeônico, por meio das concentraçôes orfeônicas promovidas durante o governo de Getúlio Vargas. Após cinco meses na instituição, foi realizada uma demonstração pública com uma massa coral de I8.000 vozes, constituídas por alunos de escolas primárias, das escolas técnico-secundárias, do Instituto de Educação e do Orfeão de Professores. Muitas dessas concentraçóes orfeônicas promovidas por VillaLobos traziam no repertório cançôes com acentuado teor nacionalista. Isso fez com que críticas recaíssem a este ensino e ao governo ditatorial de Getúlio Vargas, no período do Estado Novo, uma vez que eram feitas comparaçôes a práticas semelhantes aplicadas na Alemanha nazista de Hitler e na Itália fascista de Mussolini.

Em 1943, o maestro Villa-Lobos deixou a superintendência do Distrito Federal e fundou o Conservatório Nacional do Canto Orfeônico, de âmbito federal, com a finalidade de formar professores e de orientar o ensino musical em todo o país. Dessa forma, o maestro se preocuparia em oferecer as diretrizes para o ensino da música e do canto orfeônico nas escolas brasileiras. Villa-Lobos manteve uma posição de destaque no ensino de canto orfeônico do país, sendo citado em diversos livros didáticos da disciplina, como por exemplo, na obra: Noçóes de música e canto orfeônico, 
voltado para a $\mathrm{I}^{\mathrm{a}}$ série do curso ginasial, de Maria Elisa Leite Freitas, no ano de I94I, que apresenta Villa-Lobos como

[...] uma das maiores glórias da música nacional, aquele que, segundo Alberto Nepomuceno, achou a chave da verdadeira música brasileira, enquanto que êle achara apenas a porta, devemos, portanto a organização definitiva do ORFEÃO, na capital do Brasil, dum orfeão único que deverá, mais tarde, unir num só côro todas as vozes brasileiras para, sob uma só e mesma orientação, aprender a cantar as grandezas da Pátria e saber cantando defende-la e glorifica-la pelo trabalho honesto e inteligente, cumprindo assim, o compromisso ditado por Roquette Pinto e assinado por todos os orfeonistas: PROMETO DE CORAÇÃO SERVIR À ARTE, PARA QUE O BRASIL POSSA, NO FUTURO, TRABALHAR CANTANDO (FREITAS, I94I, p.I8, grifos do autor).

A ideia de trabalhar cantando relacionava-se a outra grande preocupação do governo getulista: o trabalho. A música serviria como uma forma de compensação ao trabalho. Villa-Lobos também pretendia atingir os operários, que eram frequentemente convidados a participar das concentraçôes orfeônicas promovidas pelo maestro durante as décadas de I930 e 1940. O apoio para as classes operárias urbanas, sempre foi um dos focos da política getulista, realidade que não acontecia durante a política anterior ao golpe dado pelo grupo de Vargas, em 1930.

\section{Conclusáo}

O ensino de música sempre esteve presente na história da educação brasileira, porém em alguns momentos com maior destaque do que em outros. No período em que o canto orfeônico foi defendido pelos escolanovistas Anísio Teixeira e Fernando de Azevedo e pelo maestro Heitor Villa-Lobos, o ensino de música prosperou na educação brasileira, contudo não o suficiente para se propagar até nosso tempo, sendo substituída pela Educação Artística, na década de I970. Nos dias atuais existe uma grande 
preocupação com o ensino de música nas escolas, principalmente após a publicação da Lei no II.769, de I8 de agosto de 2008, que tornou novamente obrigatória a presença da música dentro das escolas básicas brasileiras. Contudo, nota-se que essas instituições ainda não estáo preparadas integralmente para a aplicação de tal legislação, impedidas pela carência de materiais, espaços adequados para a prática musical e, principalmente, de professores qualificados para atuar com música na educação básica.

\section{Nota}

I A política café com leite recebeu esse nome em razão da estreita aliança política entre São Paulo e Minas Gerais, respectivamente, grandes produtores de café e leite. Esses estados detinham os dois maiores colégios eleitorais do país e elegeram entre I894 e I930, nove dos doze presidentes que governaram o Brasil.

\section{Referências}

AZEVEDO, F. A cultura brasileira: introdução ao estudo da cultura no Brasil. 4. ed. Brasília, DF: Universidade de Brasília, I963.

. Novos caminhos e novos fins: a nova política da educação no Brasil. Subsídios para uma história de quatro anos. 3. ed. São Paulo: Melhoramentos, I958.

BARRETO, C. B. B. Côro orfeão. São Paulo: Companhia Melhoramentos, I938.

CHASTEAU. Liçóes de pedagogia. Tradução de Antonio Figueirinhas. Porto: Ária Figueirinhas, I899.

CHERVEL, A. História das disciplinas escolares: reflexôes sobre um campo de pesquisa. Teoria e educação, Porto Alegre, n. 2, p. 177-229, 1990.

CONTIER, A. D. Passarinhada do Brasil: canto orfeônico, educação e getulismo. Bauru: EDUSC, I998.

FONTERRADA, M. T. O. De tramas e fios: um ensaio sobre música e educação. 2. ed. São Paulo: UNESP; Rio de Janeiro: FUNARTE, 2008.

FREITAS, M. E. L.; TEITEL, S. F. Noçôes de música e canto orfeônico: I a série. Papelaria, I94I.

GOODSON, I. F. Currículo: teoria e história. Petrópolis: Vozes, I995. 
HOBSBAWN, E. J. Naçóes e nacionalismo desde 1780: programa, mito e realidade. Rio de Janeiro: Paz e Terra, I990.

HOBSBAWN, E.; RANGER, T. A invenção das tradições. 2. ed. Rio de Janeiro: Paz e Terra, I997.

JANNIBELLI, E. D. A Musicalização na escola. I. ed., Estado da Guanabara, abr. I97I.

KIEFER, B. Villa-Lobos e o modernismo na música brasileira. 2. ed. Porto Alegre: Movimento; Brasília: INL, 1986.

SEVCENKO, N. Literatura como missão: tensóes sociais e criação cultural na primeira república. São Paulo: Brasiliense, I999.

. Orfeu extático na metrópole: São Paulo, sociedade e cultura nos frementes anos 20. São Paulo: Companhia das Letras, I992.

VILLA-LOBOS, H. Educação musical. Boletim Latino Americano de Música. Rio de Janeiro, v. I/6, p. 515-588, abr. 1946.

Apelo ao chefe do Governo Provisório da República Brasileira. Presença de Villa-Lobos. Rio de Janeiro, v.7, p. 85-87, 1973.

Recebido em I8 mar. 2012 / Aprovado em 24 abr. 2012

\section{Para referenciar este texto}

LEMOS JÚNIOR, W. História da educação musical e a experiência do canto orfeônico no Brasil. EccoS, São Paulo, n. 27, p. 67-80. jan./abr. 2012. 